\title{
EL SENTIDO MORAL DEL IMPERIO DE LA LEY: TESIS Y CONSECUENCIAS
}

\author{
Francisco Javier Ansuategui Roig \\ Universidad Carlos III
}

\begin{abstract}
bordaré algunos aspectos de la argumentación que Francisco LAPORTA ha desarrollado sobre la noción de imperio de la ley, de la que se pueden extraer consecuencias que afectan a la relación entre el Derecho y la moral. Con ello subrayaré —entre otras cosas - la centralidad, en el panorama de los problemas iusfilosóficos, de los temas sobre los que LAPORTA se ha interesado.
\end{abstract}

1. La manifestación más importante de la preocupación de LAPORTA por el tema es el libro El imperio de la ley. Una visión actual (2007) en donde se retoman argumentos desarrollados anteriormente. Cada cual tiene sus preferencias a la hora de identificar temas en los que centrar la atención investigadora en el amplio marco de la filosofía del Derecho. Hay cuestiones más periféricas que otras, que ocupan por el contrario un lugar central. Más allá de las «modas» que en ocasiones pueden centrar la atención del gremio iusfilosófico, hay cuestiones que ocupan un lugar fundamental en nuestra materia. Así, la centralidad de la relación entre la razón y la voluntad, expresión de dos dimensiones del Derecho que aparecen constantemente, con perfiles en ocasiones novedosos, en los problemas principales que nos planteamos en nuestro ámbito (ANSUATEgui Roig, 2013). Dos cuestiones se derivan de ahí: la relación entre el Derecho y el Poder y la relación entre el Derecho y la moral. Son ámbitos que centran la atención de aquel que se aproxima al Derecho en perspectiva filosófica y que condicionan la forma de conceptualizar y justificar el Derecho.

La reflexión sobre el imperio de la ley implica plantearse el tema del control jurídico del Poder e invita a asumir una posición respecto a la relación entre el Derecho y la moral. Quien se ocupa durante su carrera académica del tema no ha centrado su atención precisamente en cuestiones que se pudieran considerar periféricas o parroquiales.

2. La noción de imperio de la ley puede ser entendida de diferentes maneras. Cabe un concepto estricto y un concepto amplio. El primero, hace referencia a la reivindicación del valor y de la posición de una norma específica — la ley- que ocupa una posición determinada en el sistema y que es expresión de la voluntad política del legislador. El segundo, supone una reivindicación del valor del Derecho como modelo de organización de las conductas que recurre a las reglas como estrategia normativa. Optar por alguna de estas dos posibilidades no es intrascendente a la hora de interpretar la relación —en términos de semejanzas o diferencias- entre el Estado de Derecho y el Estado constitucional. Frente al «cambio genético» al que se refiere ZAGREBELSKY 
para caracterizar la superación del Estado (legislativo) de Derecho por parte del Estado constitucional, cabe defender que este es un modelo evolucionado y complejo de aquel (con una profundización de las estrategias limitativas del Poder), conservándose la idea principal, el imperio del Derecho, que ahora se presenta en forma de imperio de la Constitución.

Creo que LAPORTA asume un planteamiento respecto al sentido del imperio de la ley más cercano al concepto estricto, presentándose como un «legalista», quizás no perfecto (LAPORTA, 2007: 14). En tiempos de constitucionalismo como los que corren, dicha caracterización puede ser problemática para algunos. Pero se trata de entender qué se quiere decir cuando se hace referencia al legalismo. Puede parecer problemático un legalismo que nos propone abandonar la «explicable obsesión por la Constitución» (LAPORTA, 2007: 14), o la excesiva «condescendencia» de algunos respecto a «ciertos ingredientes que se estiman novedosos de los órdenes jurídicos presididos por una Constitución» (LAPORTA, 2008: 148). Condescendencia y obsesión entendidos como rasgos del ambiente jurídico y doctrinal de nuestros días. Es problemático si supone desconocer las consecuencias e implicaciones — jurídicas y políticas- que para la teoría de la producción normativa, la teoría de la norma, de la interpretación y aplicación del Derecho, por ejemplo, derivan de la naturaleza constitucional de nuestros sistemas. Pero es diferente reivindicar la centralidad — que no supremacía o superioridad - de la ley, su legitimidad, su potencialidad como elemento regulador de las conductas humanas, con una capacidad de responder a demandas de carácter ético en una superación de un discurso estrictamente formalista (LAPORTA, 2007: 167). Reivindicar el valor de la ley como estrategia de regulación del comportamiento frente a otras posibilidades, atribuyendo valor a esta forma de entender el Derecho, puede ser una buena presentación del legalismo.

3. LAPORTA considera que la idea de imperio de la ley está basada en una teoría de la autonomía personal, fundamento moral del imperio de la ley, y constituida por cuatro componentes: la libertad negativa para llevar a cabo acciones, el control racional de la satisfacción de preferencias de acuerdo con su jerarquía estratificada, la proyección de las decisiones reflexivas en el tiempo y la conformación de planes de vida generales y abstractos interrelacionados (LAPORTA, 2007: 17-37).

La idea de autonomía supone el reconocimiento del sujeto como protagonista cuando planifica y proyecta sus acciones y su trayectoria, e implica capacidad de autogobierno, entendida como un ideal regulativo, «en el sentido de que toda nuestra comprensión de la cultura descansa en la presuposición de que es deseable que los seres humanos se definan a sí mismos a través de su propia capacidad de decisión» (LAPORTA, 2007: 37). Somos «criaturas planificadoras» (LAPORTA, 2007: 32). Esta dimensión planificadora se puede ver dificultada por el carácter social del individuo, inserto en una sociedad en la que hay un gobierno que produce normas coactivas: «Cuando estoy sujeto a normas [...] no soy un agente moral autónomo, porque ser un agente con esas características parece excluir, por definición, la acción del poder político sobre mi conducta» (LAPORTA, 1994: 137). Si el principio de autonomía es una exigencia moral, la inclusión en una sociedad parece también algo inevitable. Es la tensión entre algo exigido y algo inevitable, a la que se ha referido Ernesto GARZÓN VALDÉS: «El gran desafío teórico con el que se encuentra la teoría moral y política del liberalismo es cómo 
armonizar su suposición básica según la cual los individuos, en tanto seres autónomos, procuran formular sus planes de vida privilegiando la realización de sus propios intereses, con el establecimiento necesario de un orden social heterónomo que preserve esta autonomía» (GARZÓN VALDÉS, 2000: 10).

Esta tensión se pretende gestionar a través de la articulación del poder político y del Derecho de un modo prudencial; constatada la existencia de conflictos de intereses en el grupo humano, es necesaria la institución de una autoridad que pueda actuar disuasoriamente y que pueda ejercer la coacción y el monopolio en el uso legítimo de la fuerza. Pero de la existencia de esa autoridad también se pueden derivar peligros para la autonomía personal: «La suerte de los propósitos y proyectos de los seres humanos bajo un poder ilimitado de estas características no sería, desde luego, muy envidiable y la dignidad del hombre entendida como autonomía individual estaría supeditada nuevamente a los excesos de un mecanismo tan veleidoso, insaciable e impredecible como el que más» (LAPORTA, 1994: 137). Para evitar estos peligros existen tres ideales básicos, de carácter moral: el imperio de la ley, los derechos del hombre y el principio democrático.

¿Cómo explica LAPORTA la relación que existe entre imperio de la ley y autonomía personal? Para él, el imperio de la ley constituye un «universo ético»; no es algo consustancial a la existencia del Derecho, sino un «postulado metajurídico»: «Una exigencia ético-política o un complejo principio moral que está más allá del puro derecho positivo»; en definitiva, su ámbito no es el del Derecho que es, sino el del Derecho que debe ser (LAPORTA, 1994: 135).

Para comprender la vida cotidiana y las decisiones que los individuos toman de manera ordinaria es necesario tener en cuenta el condicionamiento derivado de la existencia de normas jurídicas. El Derecho puede facilitar esas decisiones o dificultarlas. LAPORTA asume la distinción — apoyada en la diferenciación entre tipos de racionalidad desarrollada por ELSTER - entre dos contextos en los que se adoptan decisiones: el paramétrico (estable, constante, fijo) y el estratégico (cuyos componentes están sometidos a variaciones). El primero asegura la predecibilidad en mayor medida. El Derecho tiene mucho que decir a la hora de la configuración de los contextos de decisión como paramétricos o estratégicos. El imperio de la ley permite que el Derecho constituya contextos paramétricos de decisión, creando condiciones de estabilidad que permiten al individuo adoptar decisiones en un marco de certeza, previsibilidad y predecibilidad. Se tienen en cuenta los elementos del contexto y sino las consecuencias de sus decisiones y acciones. Desde el momento en que los contextos de decisión dejan de ser estratégicos para convertirse en paramétricos, podemos generar expectativas basadas en la probabilidad y en la regularidad.

Para que la constitución de dichos contextos paramétricos pueda tener lugar a través del imperio de la ley, el Derecho debe constituirse de cierta manera: 1) debe estar constituido por un conjunto de normas, entendidas como reglas, ya que solo así se pueden crear condiciones de regularidad en el marco de la cuales los individuos puedan adoptar decisiones en contextos paramétricos; 2) las normas deben tener una determinada estructura: deben ser emitidas por una autoridad reconocida y ser generales, prospectivas, estables, claras y ciertas; 3 ) en relación con la interpretación y aplicación del Derecho, el imperio de la ley exige determinados requisitos institucionales, condi- 
ciones de imparcialidad, teniendo en cuenta determinadas exigencias argumentativas. El principal requisito institucional es el de la separación de poderes, que garantiza la existencia de una institución independiente a la que acudir cuando se producen casos de violación del Derecho o problemas en la interpretación del mismo, pudiendo asegurar la autonomía individual desde el momento en que se sabe que nadie va a poder «establecer limitaciones, atribuir responsabilidades ni acordar sanciones que no estuvieran previstas de antemano por la norma» (LAPORTA, 1994: 143). Las condiciones de imparcialidad se identifican con los denominados «principios de justicia natural», tendentes a asegurar la imparcialidad del juez en el proceso y la igualdad de las partes. Las exigencias de argumentación tienen que ver con la primacía del razonamiento deductivo, que toma como premisa básica a las normas jurídicas, entendidas como reglas generales y ciertas, excluyendo preferencias personales y premisas fácticas apoyadas en hechos no probados.

Frente a una concepción instrumental del imperio de la ley (para RAz el imperio de la ley es un requisito para que el Derecho cumpla sus fines - guiar las conductas- para lo cual debe estar configurado de manera que pueda efectivamente guiar esas conductas, sin que ello implique la calificación moral de esos fines) (RAZ, 1982), LAPORTA no presta atención a esta concepción instrumental, aunque reconoce que la satisfacción de las exigencias del imperio de la ley es compatible con grandes dosis de injusticia (LAPORTA, 2002: 127). Para él, el imperio de la ley constituye un universo ético: es un instrumento de garantía de la autonomía y de la dignidad humanas. La garantía de la dignidad es una consecuencia del imperio de la ley: el Derecho debe configurarse de acuerdo con sus exigencias porque ello es imprescindible para lograr su objetivo (la guía de las conductas), y como consecuencia de ello se garantiza la dignidad. De lo contrario, se podría estar afirmando que la finalidad directa del Derecho es garantizar la dignidad. Desde un punto de vista normativo puede ser así, pero no desde un punto de vista descriptivo. Para LAPORTA el Derecho debe garantizar la dignidad y la autonomía; pero para ello es necesario que esté configurado de determinada manera.

4. La teoría del imperio de la ley presentada por LAPORTA tiene connotaciones que afectan al problema de la relación entre Derecho y Moral, en concreto a la tesis de la separación. De ella se pueden derivar consecuencias respecto a la adscripción iusnaturalista o positivista de sus postulados.

Se afirma, de una parte, que los requisitos del imperio de la ley, y la misma idea de imperio de la ley, son una condición necesaria de la juridicidad: un determinado grado de cumplimiento de las exigencias del imperio de la ley es imprescindible no para la justicia del Derecho, sino para su misma existencia. El imperio de la ley es el de las reglas: aquí se constata la contradicción entre el concepto de Derecho y la idea de arbitrariedad. Por otra, se presenta una lectura moral del imperio de la ley, merecedor de valoración moral positiva a partir de su estatus de condición necesaria de la satisfacción de las exigencias de la autonomía personal. Si se afirma el sentido moral del imperio de la ley, y al mismo tiempo su relación necesaria con el concepto de Derecho, surge la pregunta sobre la relación entre el Derecho y la moral que se está defendiendo. Si el imperio de la ley tiene un valor moral y su existencia es imprescindible en el Derecho, que se distingue de la arbitrariedad, entonces el Derecho tiene un rasgo necesario 
que tiene que ver con su valor moral: estaríamos afirmando la relación necesaria entre el Derecho y la moral.

En este punto es posible referirse a la interpretación de la tesis de la separación y a la distinción entre diversas acepciones del iusnaturalismo. Creo que la adecuada interpretación de la tesis de la separación conceptual es aquella que afirma la no necesaria conexión conceptual entre el Derecho y la moral considerada correcta. ALEXY diferencia dos versiones de la tesis de la conexión necesaria (ALEXY, 1994: 79): la débil (la «tesis moral»), señala que existe una relación necesaria entre el Derecho y alguna moral, y la fuerte afirma la relación necesaria entre el Derecho y la moral correcta. La tesis débil no supone la negación de la tesis de la separación conceptual entre el Derecho y la moral, siempre que estemos hablando de moral correcta. De la misma manera, no creo que la tesis débil sirva para demostrar la conexión necesaria entre el Derecho y la moral, por lo menos en el sentido que a dicha propuesta le ha dado el iusnaturalismo, vinculado a la afirmación de la necesaria evaluación moral positiva que merece el Ordenamiento a partir de su concurrencia con la moral, identificada con el Derecho natural. Así, no habría contradicción entre la afirmación de la conexión entre el Derecho y la moral y la tesis débil. Afirmar que en un Ordenamiento siempre vamos a encontrar planteamientos morales no implica afirmar: 1) que esos planteamientos morales deben ser necesariamente unos concretos y no otros, y 2) que esos planteamientos morales son correctos desde el punto de vista de una moral crítica o esclarecida. La existencia de dimensiones morales en el Derecho no implica necesariamente corrección moral.

Podemos hacer referencia también a la distinción entre iusnaturalismo débil e iusnaturalismo fuerte, que en realidad es una manifestación de la distinción entre iusnaturalismo deontológico y ontológico (PASSERIN D'ENTREVES, 1962: 161 y ss.). El primero establece una conexión necesaria entre el Derecho y la moral ya que aquel es un medio para alcanzar fines u objetivos (paz, seguridad, certeza) que merecen una valoración moral positiva. Son estos los que tienen un carácter moral que, a través de la relación medio-fin que se establece con el Derecho, repercutiría en este; el segundo predica el valor moral del Derecho, en cuanto vinculado por el Derecho natural, sin depender de su carácter instrumental.

Las exigencias del imperio de la ley tienen carácter moral en la perspectiva del iusnaturalismo débil, pues son requisitos necesarios para alcanzar objetivos apreciables moralmente. Un Derecho que cumpla con las exigencias del imperio de la ley puede tener unos contenidos que merezcan una evaluación moral negativa. Nada excluye la posibilidad de que un sistema cree condiciones de seguridad y certeza en el marco de los cuales un grupo étnico va a ser discriminado. Sus miembros disponen, con el suficiente grado de certeza, de la información sobre las consecuencias de sus actos o de su pertenencia al grupo. ¿Cómo se puede calificar lo anterior a partir de la propuesta de comprensión del Derecho presentada por el iusnaturalismo en sentido débil? Estaríamos obligados a emitir dos juicios morales: uno referido a la estructura del Ordenamiento, y otro a su contenido. En el ejemplo anterior, estaríamos ante un sistema jurídico que satisface los criterios de la moral interna del Derecho propuestos por FULLER. El juicio moral sería prima facie positivo, ya que el Derecho desarrolla una función de información, permite saber (CALAMANDREI, 2016:33); ese juicio positivo no sería posible en el caso de los contenidos normativos. 
Un Ordenamiento que satisfaga las exigencias del imperio de la ley puede ser considerado injusto o inmoral. Entre un iusnaturalismo débil y un positivismo que afirme la no necesaria relación entre el Derecho y la moral correcta existen diferencias que tienden a difuminarse. Esto puede ser un indicio de que, realmente, en la Filosofía del Derecho las etiquetas no son tan importantes como las tesis que se esconden tras las mismas. No creo que Francisco LAPORTA tenga reparos frente a esta afirmación.

\section{REFERENCIAS}

ALEXY, R., 1994: El concepto y la validez del Derecho, Barcelona: Gedisa.

Ansuategui Roig, F. J., 2013: Razón y voluntad en el Estado de Derecho. Un enfoque filosóficojurídico, Madrid: Dykinson.

Calamandrei, P., 2016: Sin legalidad no hay libertad, Madrid: Trotta.

GARZÓN VALDÉS, E., 2000: «Hipocresía, simpatía y Estado de Derecho», Claves de razón práctica, núm. 101.

LAPORTA, F. J., 1994: «Imperio de la ley. Reflexiones sobre un punto de partida de Elías Díaz», Doxa, I/15-16.

- 2002: «Imperio de la ley y seguridad jurídica», en E. DíAz y J. L. Colomer (eds.), Estado, justicia, derechos, Madrid: Alianza.

- 2007: El imperio de la ley. Una visión actual, Madrid: Trotta.

- 2008: «Imperio de la ley y constitucionalismo. Un diálogo entre Manuel Atienza y Francisco Laporta», El Cronista del Estado Social y Democrático de Derecho, Iustel, núm. 0.

Passerin D'ENTReVes, A., 1962: La dottrina del diritto naturale, Milano: Edizioni di Comunità.

RAZ, J., 1982: «El Estado de Derecho y su virtud», en id., La autoridad del Derecho, trad. y notas de R. Tamayo Salmorán, México: UNAM. 